\title{
The Evaluation of Osseointegration of Dental Implant Surface with Different Size of $\mathrm{TiO}_{2}$ Nanotube in Rats
}

\author{
Young-Ah Yi, ${ }^{1}$ Young-Bum Park, ${ }^{1}$ Hyunmin Choi, ${ }^{1}$ Keun-Woo Lee, ${ }^{1}$ Sun-Jai Kim, ${ }^{2}$ \\ Kwang-Mahn Kim, ${ }^{3}$ Seunghan $\mathrm{Oh}^{4}{ }^{4}$ and June-Sung Shim ${ }^{1}$ \\ ${ }^{1}$ Department of Prosthodontics, Oral Science Research Center, Yonsei University College of Dentistry, 50-1 Yonsei-ro, \\ Seodaemun-gu, Seoul 120-752, Republic of Korea \\ ${ }^{2}$ Department of Prosthodontics, Gangnam Severance Dental Hospital, Eonju-ro 612, Gangnam-gu, Seoul 135-720, Republic of Korea \\ ${ }^{3}$ Department and Research Institute of Dental Biomaterials and Bioengineering, Yonsei University College of Dentistry, \\ 50-1 Yonsei-ro, Seodaemun-gu, Seoul 120-752, Republic of Korea \\ ${ }^{4}$ Department of Dental Biomaterials, Institute of Biomaterials-Implant, Wonkwang University School of Dentistry, \\ 460 Iksandae-ro, Iksan 570-749, Republic of Korea
}

Correspondence should be addressed to June-Sung Shim; jfshim@yuhs.ac

Received 25 July 2014; Accepted 21 October 2014

Academic Editor: Sungtae Kim

Copyright (C) 2015 Young-Ah Yi et al. This is an open access article distributed under the Creative Commons Attribution License, which permits unrestricted use, distribution, and reproduction in any medium, provided the original work is properly cited.

\begin{abstract}
With the development of nanotechnology, many researches have shown that nanometer-scaled materials especially $\mathrm{TiO}_{2}$ nanotube have a positive effect on cellular behavior and surface characteristics of implant, which are considered to be crucial factors in osseointegration. However, it has not yet been verified which nanotube size is effective in osseointegration in vivo. The aim of this study was to evaluate the effect of implant surface-treated with different size of $\mathrm{TiO}_{2}$ nanotubes on osseointegration in rat femur. The customized implants (threaded and nonthreaded type), surface-treated with different diameter of $\mathrm{TiO}_{2}$ nanotubes $(30 \mathrm{~nm}, 50 \mathrm{~nm}$, $70 \mathrm{~nm}$, and $100 \mathrm{~nm}$ nanotube), were placed on both sides of the femur of 50 male Sprague-Dawley rats (6 weeks old). Rats were sacrificed at 2 and 6 weeks following surgery; then the specimens were collected by perfusion fixation and the osseointegration of implants was evaluated by radiographic and histologic analyses and removal torque value test. The mean of bone area (\%) and the mean of removal torque were different in each group, indicating that the difference in $\mathrm{TiO}_{2}$ nanotube size may influence new bone formation and osseointegration in rats.
\end{abstract}

\section{Introduction}

Titanium has been used extensively in dentistry and/or orthopedics as a material for implants since the osseointegration between titanium and bone had been found by a Swedish orthopedic surgeon, Branemark, in 1952. Following the introduction of the smooth surface implant to dentistry, dental implant has become the most well-recognized treatment option for the restoration of maxillooral functions [1] and a successful long-term survival rate of dental implant has also been documented by many researches [2].

Titanium is anticorrosive and has an excellent physical property and biocompatibility, which is partly attributed to an oxide layer formed on the surface of titanium implant in the process of manufacturing. There have been many attempts to reduce healing period and to acquire more stable osseointegration between implant and bone by altering oxide layer on the surface of titanium implant and by improving the characteristics of implant surface [3-5]. Buser et al. reported that, among many factors affecting osseointegration of implant, surface property of implant itself plays a key role in the speed of osseointegration [6, 7]. In 1996, Schwartz et al. also reported that, in order to achieve optimum osseointegration, ideal combination of surface properties of implant such as roughness, surface energy, composition, and topography is required, and these properties affect cell adhesion and propagation as well as protein adsorption in early healing period [8-10]. 
According to studies on the speed of osseointegration, implant with rough surface showed a faster and stronger osseointegration than implant with smooth surface [7]. This results from the idea that rough surface has better early mechanical fixation $[7,11,12]$ and has positive effect on adhesion and differentiation of osteoblast $[8,13,14]$. Up to date, the ideal roughness of implant surface for successful osseointegration with increased survival rate is known to be between $1 \mu \mathrm{m}$ and $2 \mu \mathrm{m}[15,16]$ and the various methods for surface treatment which gives surface roughness such as sandblasting, acid etching, and anodizing oxidation have been introduced.

In addition to altering the surface roughness of implant, there have been many attempts to increase bioactivity of implant surface by chemical treatment involving altering composition of oxide layer. Anodic oxidation on the surface of implant throughout chemical treatment was carried out for faster adhesion of calcium ion in vivo [17]. Injection of certain ions such as calcium, phosphorous, magnesium, and fluoride which stimulate the growth of bone tissue was also investigated [18-20].

Meanwhile, with the development of nanotechnology, it has been reported from many studies that the cell is very sensitive to the surrounding microenvironment. In 1997, Chen et al. reported that life of the cell is determined by geometry of surrounding microenvironment [21] and Engler et al. reported that fate of the cell is affected by elasticity of surrounding microenvironment [22]. In consequence, it has been attempted to investigate the movement, morphology, and progression of the cell by creating the same cell-sized nano structure or even smaller nano structure on the surface of the biomaterials [23]. It was reported that nanosized protrusion structure using polymer, gold cluster, and nongrained ceramic has shown good results [24-29]. In particular, among many biomaterial studies, a study using $\mathrm{TiO}_{2}$ nanotube draws attraction and has recently been of the greatest interest. This is because $\mathrm{TiO}_{2}$ nanotube is fabricated on the surface of oxide layer, becoming biocompatible. Also, it can be fabricated in different sizes and therefore, uniformed surface treatment with controlled diameter is possible. Moreover, it has an advantage that positive biological reaction can be induced in early healing period by altering the surface morphology without altering surface roughness, thereby increasing wettability [30-33].

According to previous studies on the biological application of $\mathrm{TiO}_{2}$ nanotube, the structure of $\mathrm{TiO}_{2}$ nanotube aligned perpendicular to the titanium surface has induced the formation of hydroxyapatite at nano level [34] and influenced osteoblast adhesion, proliferation, morphological growth, and even differentiation of mesenchymal stem cells into osteoblast [32, 35-38]. From previous in vitro studies, it was also reported that diameter of nanotube controlled the cell response. In Oh et al.s study, the rate of protein absorption and cell adhesion was the highest when the diameter of $\mathrm{TiO}_{2}$ nanotube was $10 \mathrm{~nm}$ whereas the shape of cells became elongated and elevated alkaline phosphatase level was found when the diameter of $\mathrm{TiO}_{2}$ nanotube was increased to $70 \mathrm{~nm}$ and $100 \mathrm{~nm}$. In contrast, Park et al. reported that among
$\mathrm{TiO}_{2}$ nanotubes with diameter between $15 \mathrm{~nm}$ and $100 \mathrm{~nm}$, $15 \mathrm{~nm}$ diameter and $30 \mathrm{~nm}$ diameter of nanotube showed the most active cell adhesion and differentiation. Cellular activities, however, were reduced in $\mathrm{TiO}_{2}$ nanotube with diameter greater than $50 \mathrm{~nm}$ and cell apoptosis occurred in $100 \mathrm{~nm} \mathrm{TiO}_{2}$ nanotube $[39,40]$.

Likewise, although numerous positive results were reported from experimental cell studies on $\mathrm{TiO}_{2}$ nanotube, yet only few were experimented in vivo $[41,42]$ and little is known regarding how the difference in diameter of nanotube affects the cells in theory and in vivo. Thus, in this study, using Sprague-Dawley rat animal model, we are aiming to investigate the effect of $\mathrm{TiO}_{2}$ nanotube with different diameter on new bone formation and osseointegration both histologically and mechanically by measuring the bone surface around the implant (\%) and the removal torque value.

\section{Materials and Methods}

2.1. Implant Design. Customized implants are designed and fabricated as below. Figure 1 shows a schematic diagram of customized implants involving nonthreaded type implant placed in right femur of the rat (Figure 1(a)) and threaded type implant placed in left femur of the rat (Figure 1(b)). Fifty implants were fabricated for each type.

2.2. $\mathrm{TiO}_{2}$ Nanotube Fabrication. Customized titanium implants were rinsed with acetone, ethanol, and distilled water. Then, $\mathrm{TiO}_{2}$ nanotubes were generated on the whole surface of implant by anodization in the mixture of $875 \mathrm{~mL}$ of $0.5 \mathrm{wt} \%$ hydrofluoric acid (Merck, NJ, USA; 48\%) and $125 \mathrm{~mL}$ of acetic acid (JT Baker, NJ, USA; 99\%, volumetric ratio $=7: 1$ ) at $5,10,15$, and $20 \mathrm{~V}$ for $1 \mathrm{~h}$ at room temperature to obtain $30,50,70$, and $100 \mathrm{~nm} \mathrm{TiO}_{2}$ nanotube, respectively (Figure 2). $\mathrm{TiO}_{2}$ nanotube fabrication was carried out at biomaterial laboratory at Wonkwang University, College of Dentistry, Seoul, Korea, and all fabricated $\mathrm{TiO}_{2}$ nanotubes were then observed by using scanning electron microscopy (SEM). After anodization, the specimens were rinsed with distilled water, dried in the oven for $24 \mathrm{~h}$ at $60^{\circ} \mathrm{C}$, and heat-treated in the air for $2 \mathrm{~h}$ at $500^{\circ} \mathrm{C}$ (temperature rising and cooling speed: $1^{\circ} \mathrm{C} \mathrm{min}^{-1}$ ).

2.3. Experimental Animals and Classification of Experimental Groups. Fifty male Sprague-Dawley rats (body weight $200 \mathrm{~g}$, 6 weeks old) were divided into experimental groups in which implants surface-treated with different diameter of $\mathrm{TiO}_{2}$ nanotubes $(30 \mathrm{~nm}, 50 \mathrm{~nm}, 70 \mathrm{~nm}$, and $100 \mathrm{~nm}$ ) were placed and control groups in which nontreated implants were placed. Each group is divided into 5 subgroups (total 10 subgroups) according to time of sacrifice (2 weeks and 6 weeks).

Experimental rats were housed at the animal experimental laboratory at Yonsei University, College of Dentistry, Seoul, Korea. All experiments were performed in accordance with the guidelines for animal experiments of Yonsei University College of Dentistry. 


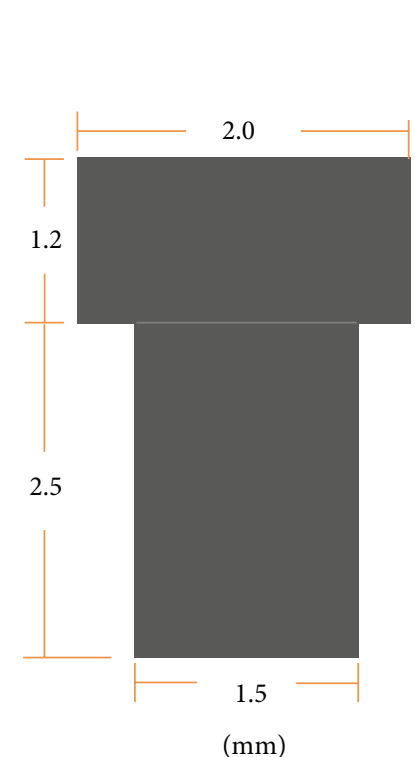

(a)

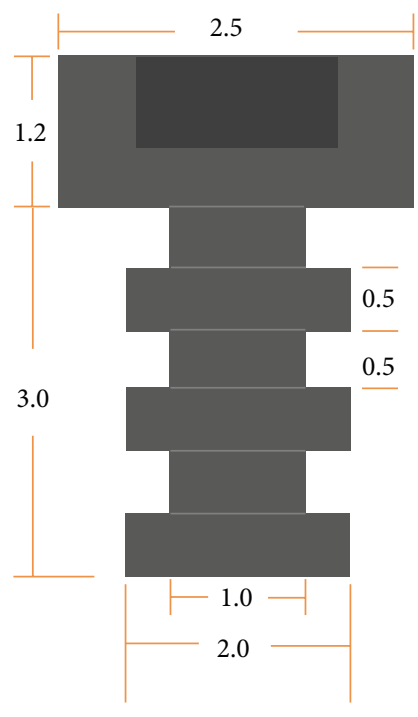

$(\mathrm{mm})$

(b)

FIgURE 1: A schematic diagram of customized implant (Add-Tech, Seoul, Korea). (a) Nonthreaded type implant for right femur and (b) threaded type implant for left femur.

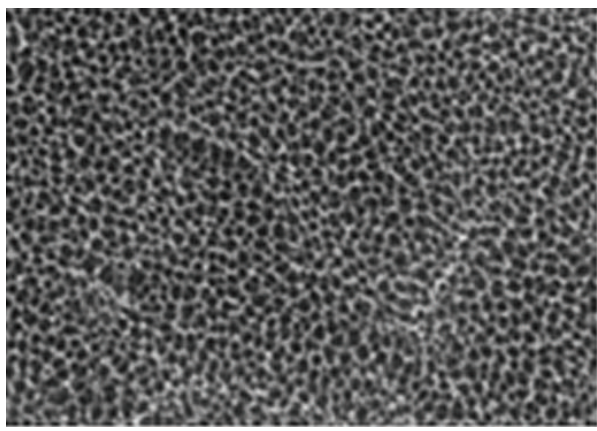

(a)

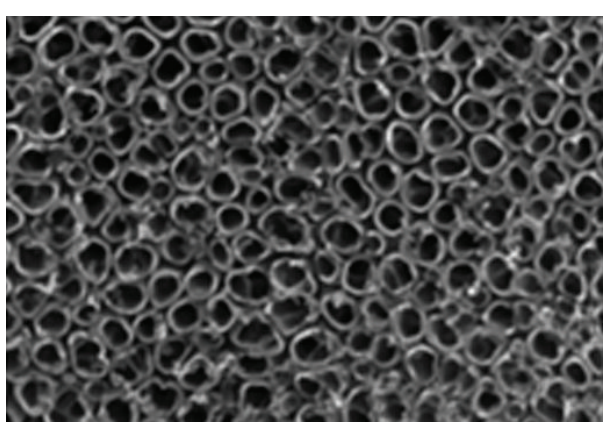

(c)

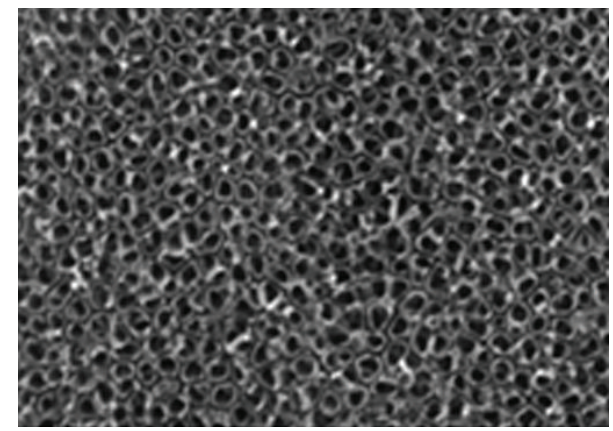

(b)

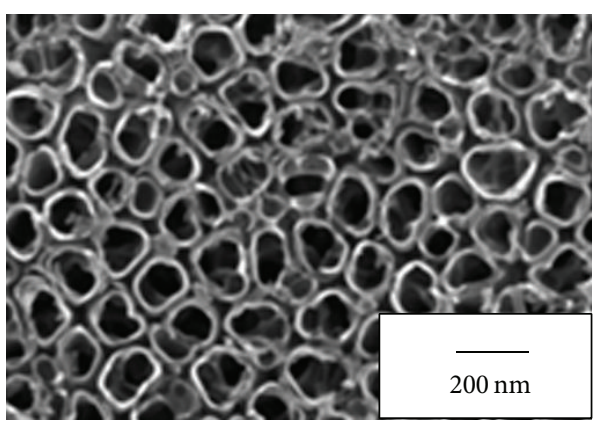

(d)

FiguRE 2: SEM images of $\mathrm{TiO}_{2}$ nanotubes with different diameters, 30 (a), 50 (b), 70 (c), and $100 \mathrm{~nm}(\mathrm{~d})$, created by controlling anodizing potentials ranging from 5 to $20 \mathrm{~V}$ (scale bar, $200 \mathrm{~nm}$ ).

2.4. Experimental Procedures. Surgical interventions were conducted under general anesthesia by intramuscular injection of an anesthetic cocktail composed of Rompun $\left(10 \mathrm{mg} \mathrm{kg}^{-1}\right)$ and Zoletil $\left(30 \mathrm{mg} \mathrm{kg}^{-1}\right)$. Surgical site was then isolated $10 \mathrm{~min}$ after injection of anesthesia by shaving and sterilizing with povidone-iodine solution. $2 \%$ lidocaine was injected subcutaneously and surgical sites were drilled in left femur and right femur with $1.5 \mathrm{~mm}$ and $2.0 \mathrm{~mm}$ in diameter, respectively, and the customized implants were then inserted into the osteotome sites until the top of the implants reached 


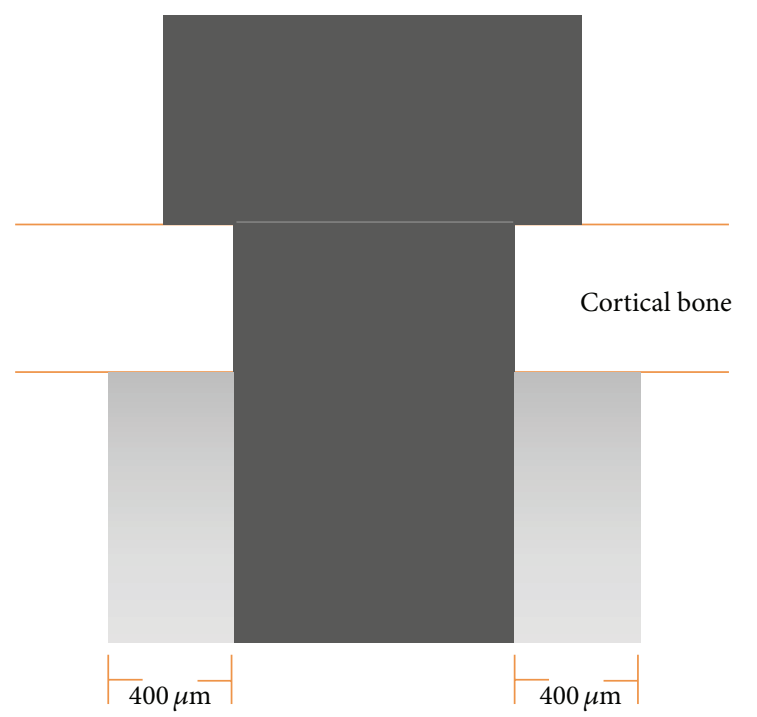

FIGURE 3: The new bone area was calculated in defined area which was designated below the cortical layer, within $400 \mu \mathrm{m}$ from the implant surface.

the peripheral bone, followed by suturing with 3.0 silk. Nonthreaded and threaded type implants were inserted on the right femur and left femur, respectively, and rats were sacrificed at 2 weeks and 6 weeks after surgical intervention. Experimental animals were perfused with $10 \%$ neutral buffered formalin under general anesthesia and sacrificed. Torque removal test was performed with the specimen collected from left femur whereas histomorphological and histomorphometric analysis were performed with the specimen collected from right femur.

2.5. Radiographic Analysis. In order to evaluate the position of implant in relation to surrounding bone and new bone formation around implant, micro CT (Skyscan 1076, Aartselaar, Belgium) was taken at $50 \mathrm{kv}$ and $30 \mu \mathrm{a}$ with $18 \mu \mathrm{m}$ distance interval.

2.6. Histomorphometric Analysis. After taking micro CT, the samples were collected from right femur which were fixed with $10 \%$ neutral buffered formalin at $4^{\circ} \mathrm{C}$ for 14 days and then decalcified with 1\% EDTA for 14 days. The decalcified samples were embedded in paraffin wax and then sectioned into $2 \mu \mathrm{m}$ thick, parallel to the axis of femur using microtome. The sectioned samples were stained with hematoxylin-eosin (H\&E) stain. The samples were then observed with a light microscope (Leica DM 2500, Leica Microsystems, Wetzlar, Germany). After samples were magnified by $\times 12.5, \times 50$ and $\times 100$ and captured accordingly, bone area were marked using image analysis software (IMT i-solution Lite version 8.1, Vancouver, BC, Canada) and calculated using Image Pro Plus 4.5 (Media Cybermetrics, Bethesda, MD, USA). The new bone was calculated in a defined area which was designated below the cortical layer, within $400 \mu \mathrm{m}$ from the implant surface (Figure 3).

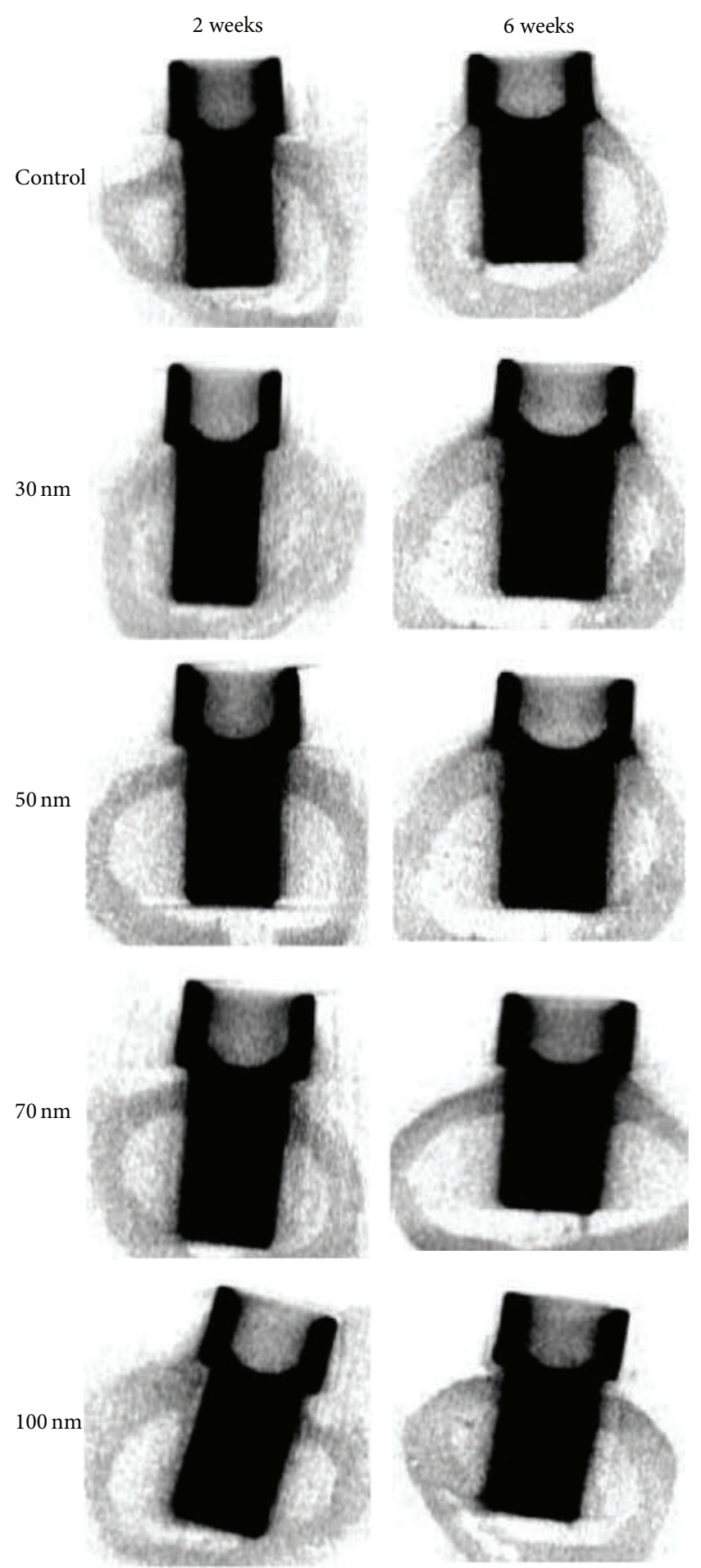

FIGURE 4: Micro CT images of representative sample of each group. All the implants were placed favorably in femur of rats.

2.7. Removal Torque Measurements. After taking micro CT, the samples collected from left femur in which threaded type implant was placed were fixed at specially designed removal torque test apparatus, connected with conventional digital torque gauge (Mark-10, MGT12, New York, USA). Implants were fixed to removal torque test apparatus, making sure 


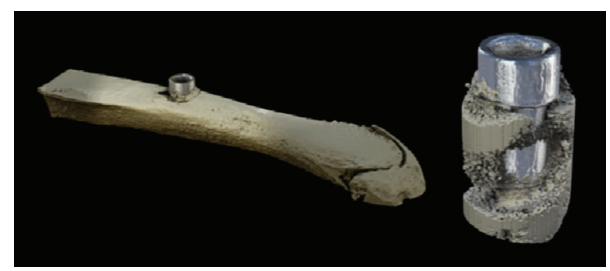

FIgURE 5: 3D reconstructed images of implant area.

implants were aligned to the axis of apparatus. Screw driver which was installed in removal torque test apparatus was then connected to the upper notch of implant and the apparatus was rotated in an anticlockwise direction. Peak value when implant-bone interface is broken was recorded.

2.8. Elemental Analysis of the Bone-Implant Interface. In order to investigate the physical strength of nanotube treated implant, implant-side interface of one sample in each group was observed using scanned electron microscope (S-3000N, HITACHI, Schamburg, IL, USA) and energy-dispersive Xray spectroscopy (EMAX, HORIBA, UK). Elemental analysis of the bone-implant interface was also performed to see the involvement of bone cell formation in bone-implant interface.

2.9. Statistical Analysis. Mean value and standard deviation of each group were calculated to see if there is a statistically significant difference in the removal torque value and area of bone (\%) of each group according to different diameter of nanotube at 2 weeks and 6 weeks. The comparison of mean value was analyzed via one-way ANOVA. All statistical analyses were performed using SPSS 18.0 statistical software.

\section{Results}

Among the total of 50 rats, one rat in control group (2 weeks) died during implant surgery due to facture of the femur. Two rats in $100 \mathrm{~nm}$ nanotube experimental group (2 weeks and 6 weeks) also died during healing period after surgery. All the rest were well healed and recovered without any significant complications.

3.1. Micro CT Scan. Having observed micro CT images of all the samples, it can be observed that all the implants were placed favorably in the femur. New bone was formed around the implant (Figure 4) and three-dimensional reconstructed images were presented in Figure 5.

3.2. Histological and Histomorphometric Analysis. Throughout $\mathrm{H} \& \mathrm{E}$ stained images, it was found that new bone was formed, encircling around the implant. In contrast to the new bone formed near cortical bone, which can be difficult to differentiate, the new bone within the sponge bone is easy to differentiate therefore and is measured. During the removal of implants, the samples with disturbed implant new interface or severely damaged samples were difficult to analyze and therefore were excluded from the histomorphometric analysis. The results showed the higher mean of bone area (\%) in $30 \mathrm{~nm}$ experimental group and in $70 \mathrm{~nm}$ experimental group at 2 weeks and 6 weeks, respectively. There was no statistically significant difference $(P>0.05)$ (Figures 6, 7, and 8).

3.3. Removal Torque Test. Among the experimental samples, the samples with new bone covered on the implant were excluded from analysis. Regardless of the diameter of $\mathrm{TiO}_{2}$ nanotube, $\mathrm{TiO}_{2}$ nanotube surface-treated group showed higher value than the control group (nontreated group). $30 \mathrm{~nm}$ experimental group and $70 \mathrm{~nm}$ experimental group at 2 weeks and 6 weeks showed the highest value, respectively; however, there was no statistically significant difference $(P>$ 0.05) (Figure 9).

3.4. Elemental Analysis of the Bone-Implant Interface. After removal torque test, in the SEM, EDX analysis of the boneimplant interface in the nanotube surface-treated experimental group, $\mathrm{TiO}_{2}$ nanotube was clearly seen on the top of implant which did not contact the bone (Figure 10(a)). In the thread area which contacted the newly formed bone, the surface consists of the layer containing $\mathrm{Ca}$ and $\mathrm{P}$ elements. (Figure 10(d)) In all the samples, nanotube was not found near the thread area of implant (Figure 10(c)).

\section{Discussions}

As recent studies reported that cells display a sensitive response to surrounding microenvironment at nano level $[21,22,43,44]$, many efforts were made to investigate the cell's behavior at nano level with a size of less than $100 \mathrm{~nm}$ [23, 25-28]. It has been reported that cell adhesion and differentiation on and near implants surface after titanium implant placement play critical roles in successful osseointegration [35-38]. Therefore, many studies are under investigation to find methods for implant surface treatment at nano level in order to enhance cell attachment and osteogenic ability of osteoblast. Of all, $\mathrm{TiO}_{2}$ nanotube, a biocompatible layer formed after titanium implant etching, has a low chance of delamination compared to other surfaces and increases the contact area with bones.

According to previous in vitro findings regarding $\mathrm{TiO}_{2}$ nanotube, by treating the surface with $\mathrm{TiO}_{2}$ nanotube, protein absorption, cell adhesion rate, and cell motility can be increased [32, 35-38]. Altering of diameter of $\mathrm{TiO}_{2}$ nanotube also induces differentiation of osteoblast from stem cells and affects the cell adhesion, osteoblast formation, and osteogenic ability $[39,40]$. Thus, even a small difference in diameter of nanotube remarkably changes cell adhesion, growth, motility, and differentiation. Therefore, the aim of this study was to investigate whether this difference in nanotube size would result in change in osseointegration in vivo and to find the optimum range of diameter of $\mathrm{TiO}_{2}$ nanotubes.

In fact, It will be more ideal to observe implant in oral cavity of animal model for in vivo study. Instead, we chose to use Sprague-Dawley rat model which has advantage of low cost that could maximize the sample size and easy management. They also have fast turnover rate of bone, which can 


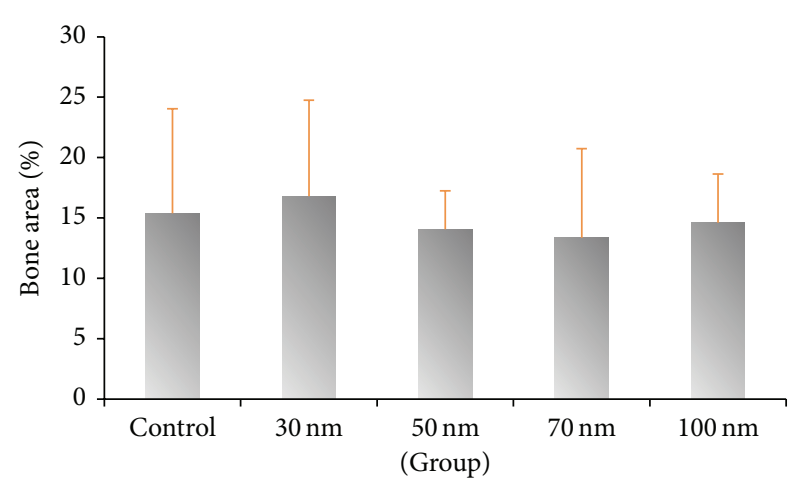

(a)

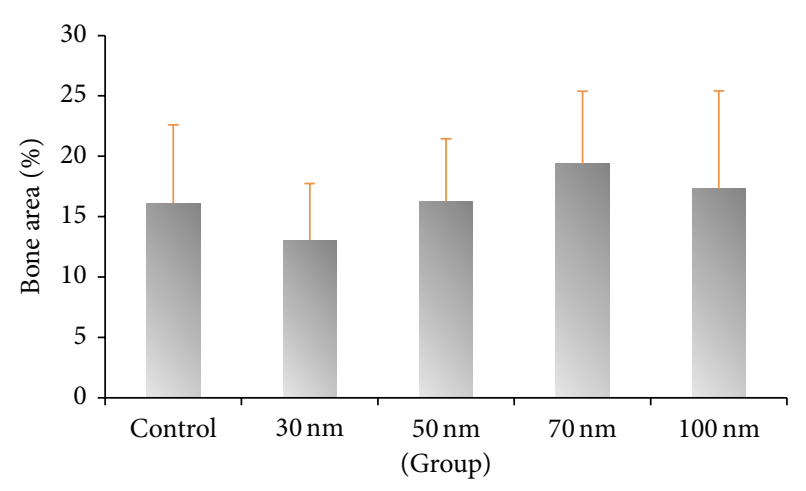

(b)

Figure 6: Measurement of bone area (\%) at 2 weeks (a) and 6 weeks (b) in defined area which is designated below the cortical layer, within $400 \mu \mathrm{m}$ far from the implant surface. The results showed the higher mean of bone area (\%) in $30 \mathrm{~nm}$ experimental group and in $70 \mathrm{~nm}$ experimental group at 2 weeks and 6 weeks, respectively $(P>0.05)$.

shorten the experimental period. Previous studies reported that in Sprague-Dawley rat model, new bone formation and osseointegration occur after 5 days and 28 days, respectively [45-47]. Therefore, in the present study, we sacrificed the rats in experimental groups at week 2 and week 6 to observe early healing status and completion of osseointegration status, respectively.

In order to evaluate new bone formation after implant placement, we used micro CT and tissue specimens to measure the amount of newly formed bone (\%) and removal torque value to analyze degree of osseointegration. All samples were examined for radiographic analysis by using micro CT prior to the preparation of tissue specimens and removal torque test and positional relationship between the femur and the implant placement were evaluated. Bone volume around the implant was also measured. However, due to potential scattering phenomena caused by titanium, the values of bone volume measured by micro CT were excluded from quantitative analysis.

After micro CT imaging, H\&E stained specimen was prepared and observed under a light microscope to measure newly formed bone around the implants. The newly formed bone was measured within $400 \mu \mathrm{m}$ from the implant surface placed spongy bone under compact bone. This is because newly formed bone in spongy bone is easier to distinguish than in compact bone. Futami et al. showed that the affected region from implant placement is within $100 \mu \mathrm{m}$ around the drilling area [47], whereas Kenzora et al. described that it is within $500 \mu \mathrm{m}$ [48]. We chose the area within $400 \mu \mathrm{m}$ to include the affected region and thick layer of triangle-shaped, newly formed bone right below the compact bone. From the histomorphometric analysis, the more bone formation was observed in the $30 \mathrm{~nm}$ experimental group sacrificed after 2 weeks and in $70 \mathrm{~nm}$ experimental group sacrificed after 6 weeks. However, there was no statistically significant difference $(P>0.05)$.

In addition, we measured removal torque value using digital torque gage. In 1991, Johansson and Albrektsson discovered that the force to remove implant was proportional to rate of bone-implant contact [49]. In this experiment, the highest torque values were obtained in the $30 \mathrm{~nm}$ experimental group sacrificed after 2 weeks and $70 \mathrm{~nm}$ experimental group scarified after 6 weeks. There was a similar pattern in both histological finding of new bone formation and result of removal torque test.

Assuming that the differences of individual subject are minimized by controlling weight, age, sex, and randomization, $30 \mathrm{~nm}$ experimental group has more new bone formation around implant and stronger bone to implant bonding strength than $70 \mathrm{~nm}$ experimental group during early healing period. However, after 6 weeks, when healing is completed, $70 \mathrm{~nm}$ experimental group revealed more new bone formation and stronger bone to implant bonding, which is in line with Park et al.s study in which the highest cell vitality and differentiation were observed in $15 \mathrm{~nm} \mathrm{TiO}$ nanotube group $[39,40]$. von Wilmowsky et al. compared $\mathrm{BIC}$ measurement and immunohistological analysis in $30 \mathrm{~nm}$ nanotube surface treated versus untreated implants in vivo using swine skull [42]. They showed that there was no bone to implant contact (BIC) difference in both groups but collagen type I formation was higher in $30 \mathrm{~nm} \mathrm{TiO}_{2}$ nanotube group. Collagen type $\mathrm{I}$ is an essential bone matrix protein during early bone formation and plays an essential role as a scaffolding protein during cell adhesion. It also has an important role in cell differentiation and morphogenesis and, therefore, increased collagen type I expression indicates the active process of early stage of bone formation. Moreover, Oh et al. compared cell behaviors using $\mathrm{TiO}_{2}$ nanotube with various diameters $(30 \mathrm{~nm}, 50 \mathrm{~nm}, 70 \mathrm{~nm}$, and $100 \mathrm{~nm})$ on titanium surface and showed that $30 \mathrm{~nm} \mathrm{TiO}_{2}$ nanotube group showed the best protein absorption and cell adhesion [32, 35]. In $70 \mathrm{~nm} \mathrm{TiO}_{2}$ nanotube and $100 \mathrm{~nm}$ nanotube group, however, nucleus and cytoplasm of osteoblast became elongated and alkaline phosphatase activity, a marker of bone formation, was increased the most among the groups. This previous report could be an explanation why $70 \mathrm{~nm}$ group sacrificed at 6th week in the present study showed increased rate of new bone formation and removal torque value. They also suggested that the reason why $\mathrm{TiO}_{2}$ nanotube treated group has better cell response compared to control group 


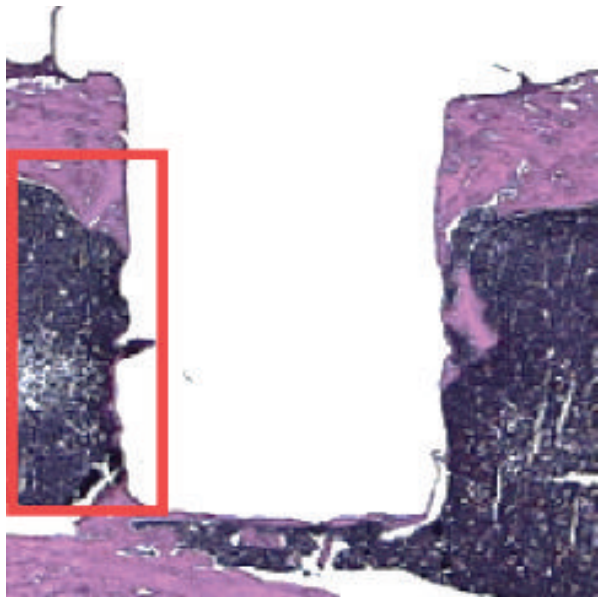

(a)

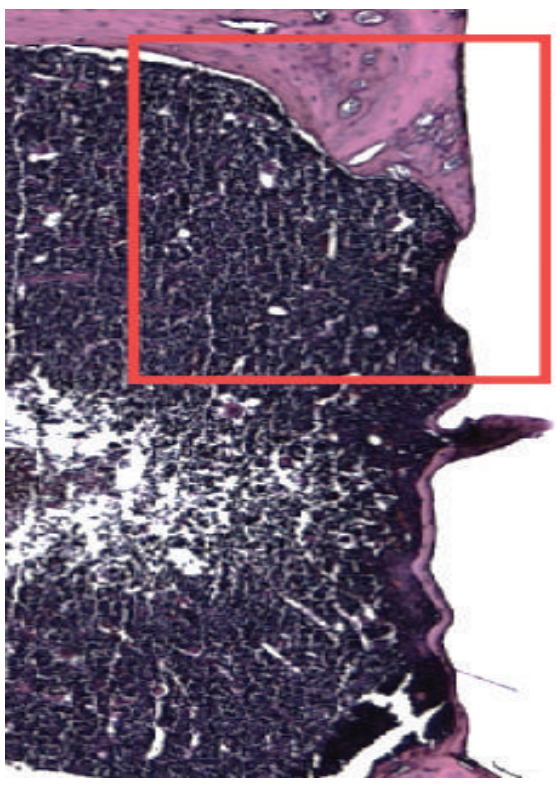

(b)

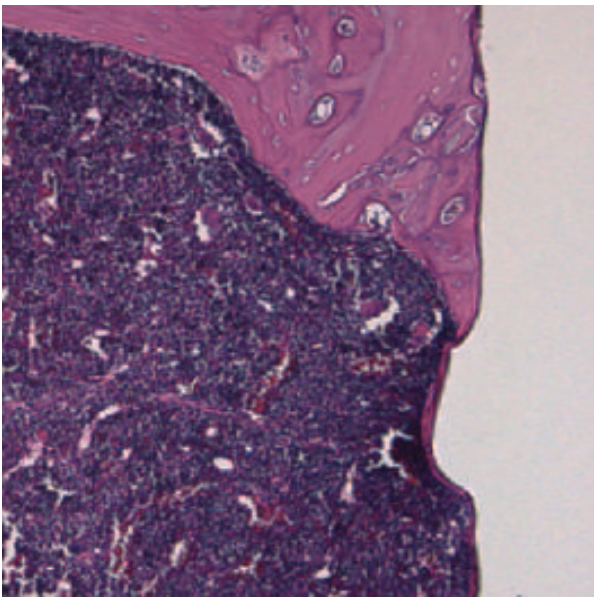

(c)

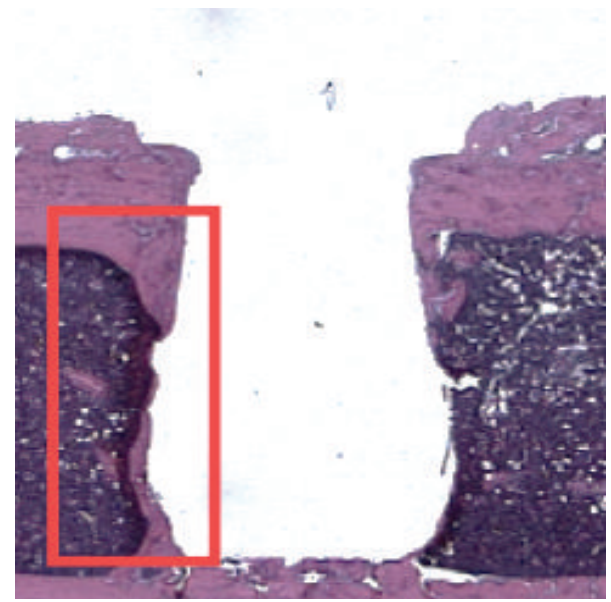

(d)

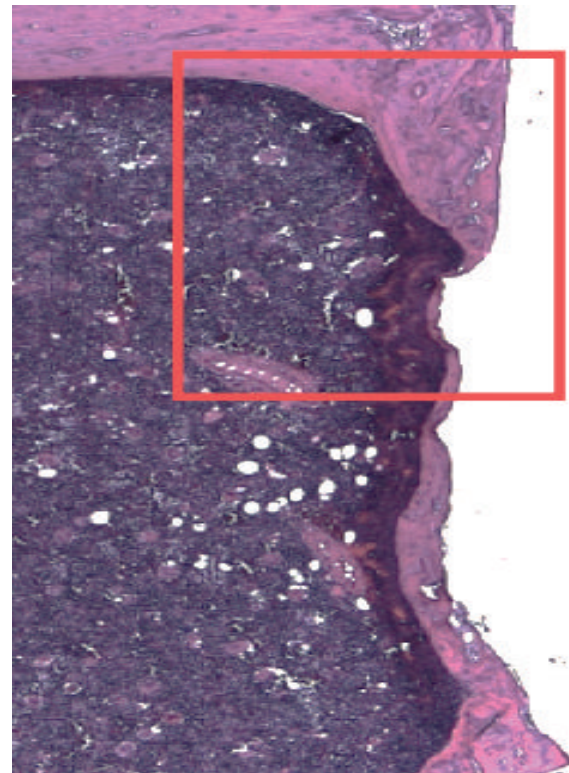

(e)

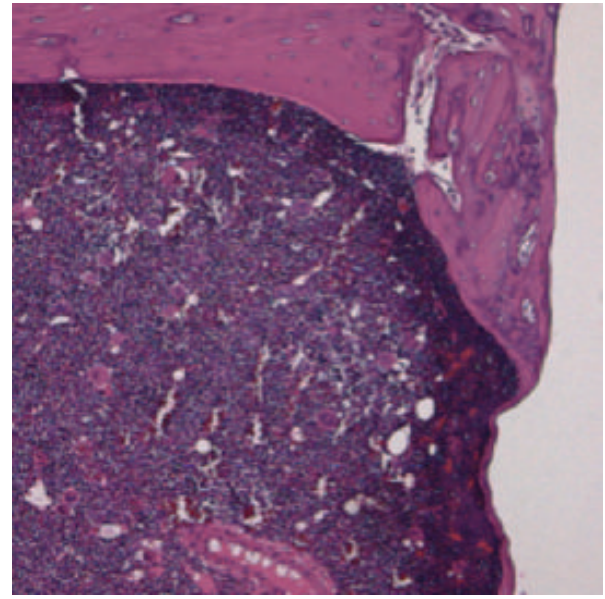

(f)

FIGURE 7: Histologic images of control ((a), (b), and (c)) and $30 \mathrm{~nm}((\mathrm{~d}),(\mathrm{e})$, and (f)) groups at 2 weeks after implantation. ((a) and (d)) H\&E stained images at lower magnification $(\times 12.5),((\mathrm{b})$ and $(\mathrm{e})) \mathrm{H} \& \mathrm{E}$ stained images of red boxes in the A\&D $(\times 50)$, and ((c) and (f)) H\&E stained images of red boxes in the B\&E $(\times 100)$. 


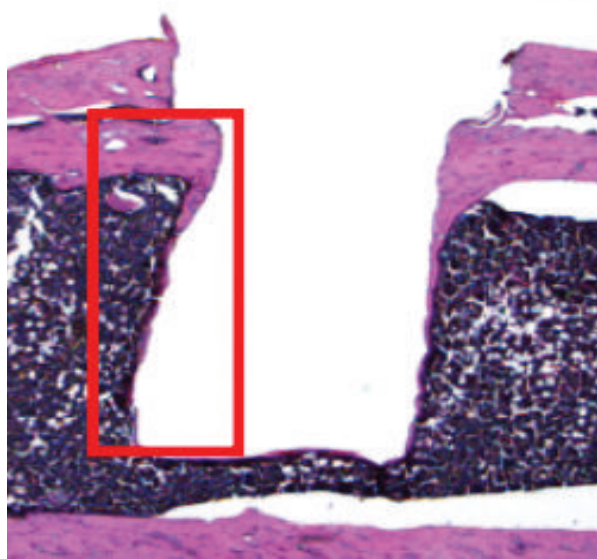

(a)

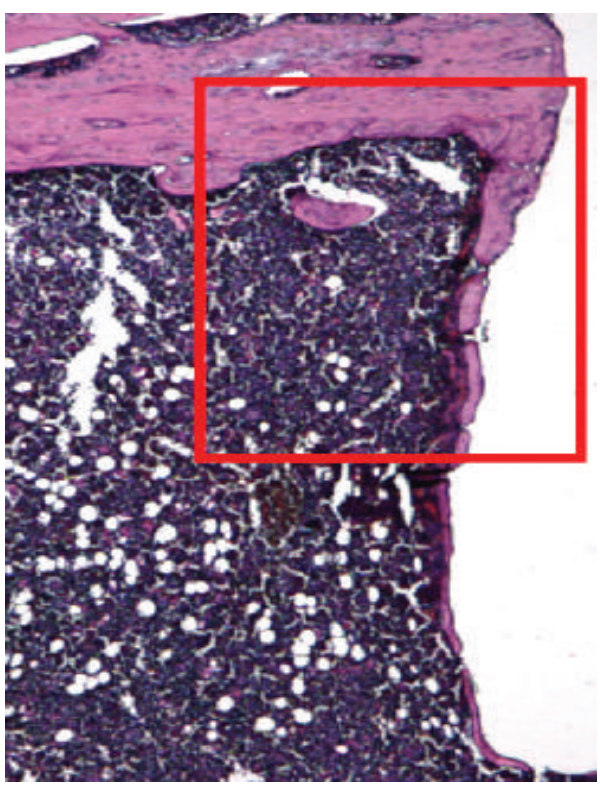

(b)

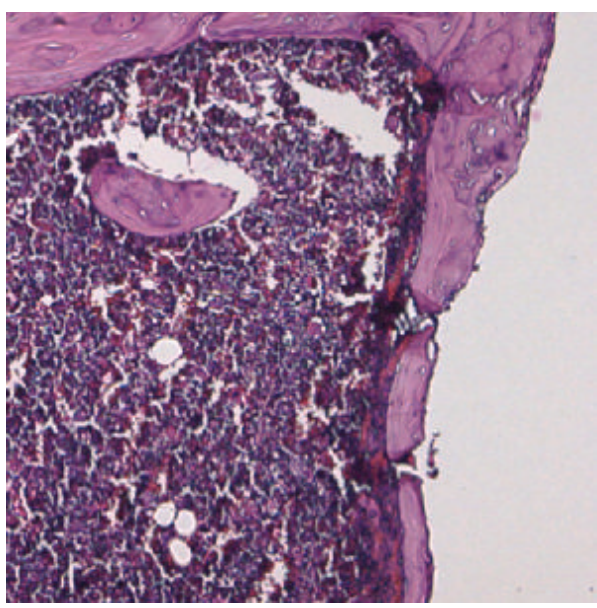

(c)

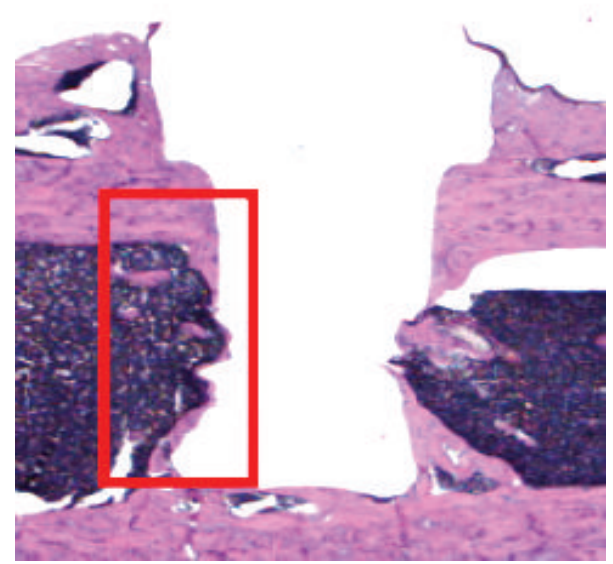

(d)

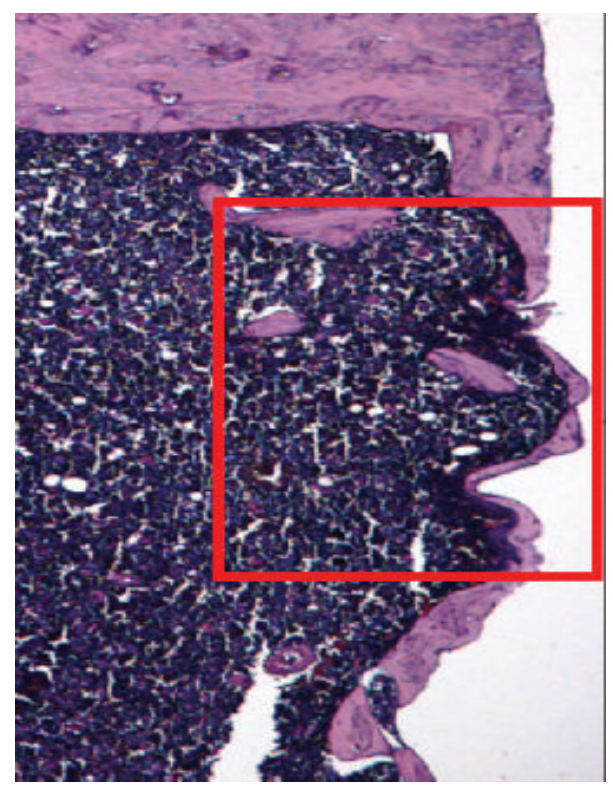

(e)

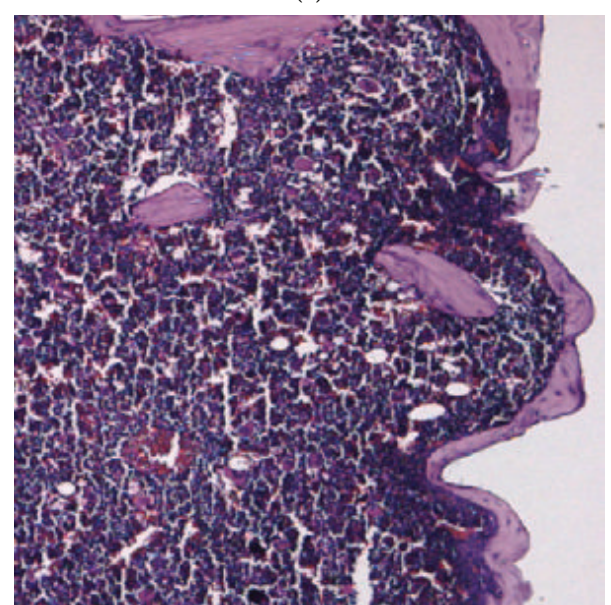

(f)

Figure 8: Histologic images of control ((a), (b), and (c)) and $70 \mathrm{~nm}((\mathrm{~d}),(\mathrm{e})$, and (f)) group at 6 weeks after implantation. ((a) and (d)) H\&E stained images at lower magnification ( $\times 12.5),((b)$ and (e)) H\&E stained images of red boxes in the A\&D ( $\times 50)$, and ((c) and (f)) H\&E stained images of red boxes in the $\mathrm{B} \& \mathrm{E}(\times 100)$. 


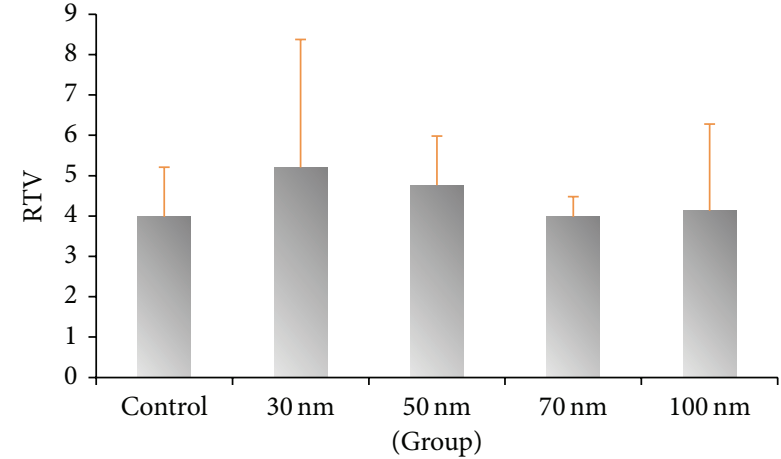

(a)

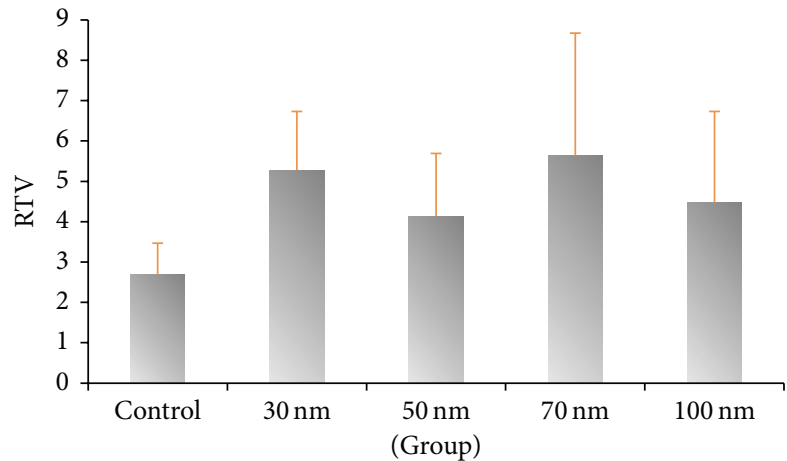

(b)

FIGURE 9: The removal torques mean value at 2 weeks (a) and 6 weeks (b) after implantation. $\mathrm{TiO}_{2}$ nanotube surface-treated groups showed higher value than the control group (nontreated group). $30 \mathrm{~nm}$ experimental group and $70 \mathrm{~nm}$ experimental group at 2 weeks and 6 weeks showed the highest value, respectively $(P>0.05)$.

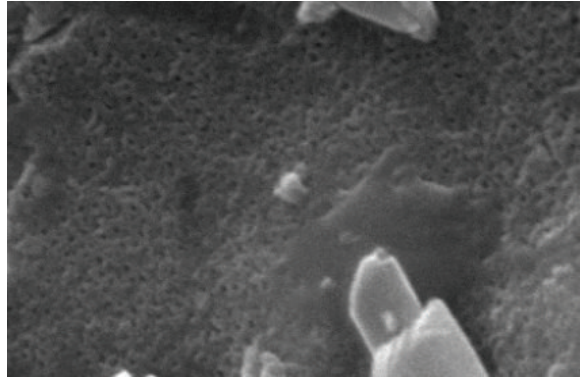

(a)

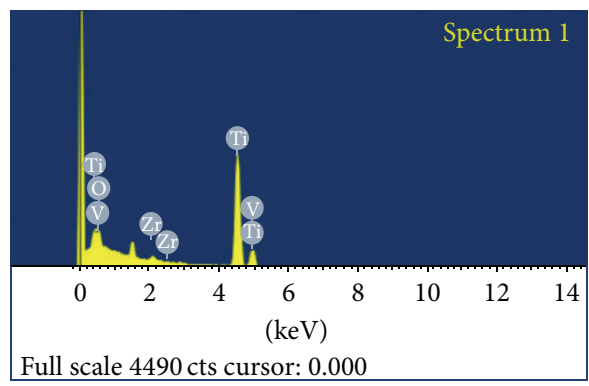

(b)

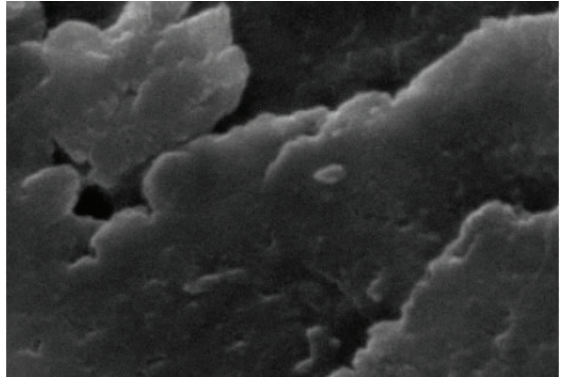

(c)

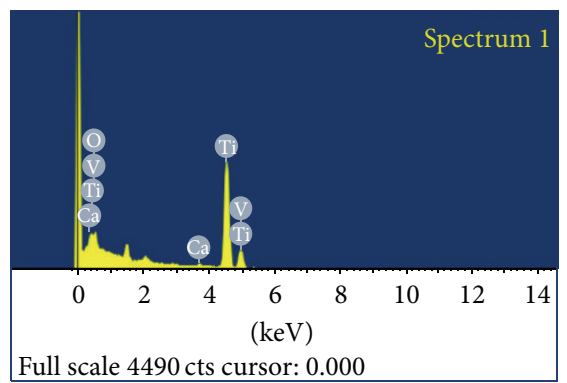

(d)

FIGURE 10: SEM image $(\times 20,000)$ (a) and comparative elemental mapping $(\times 2,000)(b)$ of the top of implant of the sample in $100 \mathrm{~nm}$ group after removal torque test. SEM image $(\times 20,000)$ (c) and comparative elemental mapping $(\times 2,000)(\mathrm{d})$ of the thread area of implant of the sample in $100 \mathrm{~nm}$ group after removal torque test showing Ca ion besides Ti and $\mathrm{O}$.

is that there exists three-dimensional space where fluid can freely flows, enabling active ion exchange that is essential for sufficient nutritional supply and cell signaling cascade. As the diameter of $\mathrm{TiO}_{2}$ nanotube becomes longer there will be more interconnecting space; therefore the surface area of $100 \mathrm{~nm}$ is three times larger than that of $30 \mathrm{~nm}$, leading to positive cell responses $[23,25]$.

This study has several limitations: small sample size for each group, placement of implant in femur which is long bone instead of maxillary or mandibular bone, and a variation of bone thickness in different area of femur [50]. However, we clearly showed the mechanical and histological difference in osseointegration depending on the diameter of $\mathrm{TiO}_{2}$ nanotube and healing period. Not only does $\mathrm{TiO}_{2}$ nanotube surface direct fate of osteoblasts during osteogenesis in early healing period after implant placement but also three-dimensional spaces inside the nanotubes might be used as a mediator, conveying specific medication or growth factors. Therefore, further study regarding treatment of $\mathrm{TiO}_{2}$ nanotube surface would be required.

\section{Conclusion}

Within the limitations of experiment, the highest mean of new bone area (\%) and the highest mean of removal torque value were observed in $30 \mathrm{~nm}$ experimental group 
and in $70 \mathrm{~nm}$ experimental group at 2 weeks and 6 weeks, respectively. Also, in comparative elemental analysis, bone compositions were found on the implant side of bone-implant interface, confirming that new bone formation had occurred. Based on the results described above, it can be suggested that difference in diameter of $\mathrm{TiO}_{2}$ nanotube may influence new bone formation and osseointegration in rats and therefore can be further utilized for clinical application.

\section{Conflict of Interests}

The authors declare no conflict of interests.

\section{Authors' Contribution}

Young-Ah Yi and Young-Bum Park equally contributed to this study. Seunghan Oh is co-corresponding author for production of $\mathrm{TiO}_{2}$ nanotube.

\section{Acknowledgment}

This study was supported by research grant of Yonsei University (8-2013-0037).

\section{References}

[1] P. I. Brånemark, B. O. Hansson, R. Adell et al., "Osseointegrated implants in the treatment of the edentulous jaw. Experience from a 10-year period," Scandinavian Journal of Plastic and Reconstructive Surgery. Supplementum, vol. 16, pp. 1-132, 1977.

[2] R. Adell, B. Eriksson, U. Lekholm, P. I. Brånemark, and T. Jemt, "Long-term follow-up study of osseointegrated implants in the treatment of totally edentulous jaws," The International Journal of Oral \& Maxillofacial Implants, vol. 5, no. 4, pp. 347-359, 1990.

[3] L.-H. Li, Y.-M. Kong, H.-W. Kim et al., "Improved biological performance of Ti implants due to surface modification by micro-arc oxidation," Biomaterials, vol. 25, no. 14, pp. 28672875, 2004.

[4] L. le Guéhennec, A. Soueidan, P. Layrolle, and Y. Amouriq, "Surface treatments of titanium dental implants for rapid osseointegration," Dental Materials, vol. 23, no. 7, pp. 844-854, 2007.

[5] V. F. Stenport and C. B. Johansson, "Evaluations of bone tissue integration to pure and alloyed titanium implants," Clinical Implant Dentistry and Related Research, vol. 10, no. 3, pp. 191199, 2008.

[6] D. Buser, T. Nydegger, T. Oxland et al., "Interface shear strength of titanium implants with a sandblasted and acid-etched surface: a biomechanical study in the maxilla of miniature pigs," Journal of Biomedical Materials Research, vol. 45, no. 2, pp. 7583, 1999.

[7] D. Buser, R. K. Schenk, S. Steinemann, J. P. Fiorellini, C. H. Fox, and H. Stich, "Influence of surface characteristics on bone integration of titanium implants. A histomorphometric study in miniature pigs," Journal of Biomedical Materials Research, vol. 25, no. 7, pp. 889-902, 1991.

[8] Z. Schwartz and B. D. Boyan, "Underlying mechanisms at the bone-biomaterial interface," Journal of Cellular Biochemistry, vol. 56, no. 3, pp. 340-347, 1994.

[9] Z. Schwartz, K. Kieswetter, D. D. Dean, and B. D. Boyan, "Underlying mechanisms at the bone-surface interface during regeneration," Journal of Periodontal Research, vol. 32, no. 1, part 2, pp. 166-171, 1997.

[10] Z. Schwartz, C. H. Lohmann, J. Oefinger, L. F. Bonewald, D. D. Dean, and B. D. Boyan, "Implant surface characteristics modulate differentiation behavior of cells in the osteoblastic lineage," Advances in Dental Research, vol. 13, pp. 38-48, 1999.

[11] K. Gotfredsen, A. Wennerberg, C. Johansson, L. T. Skovgaard, and E. Hjorting-Hansen, "Anchorage of $\mathrm{TiO}_{2}$-blasted, HAcoated, and machined implants: an experimental study with rabbits," Journal of Biomedical Materials Research, vol. 29, no. 10, pp. 1223-1231, 1995.

[12] A. Wennerberg, T. Albrektsson, B. Andersson, and J. J. Krol, "A histomorphometric and removal torque study of screw-shaped titanium implants with three different surface topographies," Clinical Oral Implants Research, vol. 6, no. 1, pp. 24-30, 1995.

[13] K. Mustafa, A. Wennerberg, J. Wroblewski, K. Hultenby, B. S. Lopez, and K. Arvidson, "Determining optimal surface roughness of $\mathrm{TiO}_{2}$ blasted titanium implant material for attachment, proliferation and differentiation of cells derived from human mandibular alveolar bone," Clinical Oral Implants Research, vol. 12, no. 5, pp. 515-525, 2001.

[14] A. Abron, M. Hopfensperger, J. Thompson, and L. F. Cooper, "Evaluation of a predictive model for implant surface topography effects on early osseointegration in the rat tibia model," Journal of Prosthetic Dentistry, vol. 85, no. 1, pp. 40-46, 2001.

[15] T. Albrektsson and A. Wennerberg, "The impact of oral implants-past and future, 1966-2042," Journal of the Canadian Dental Association, vol. 71, no. 5, pp. 327-327, 2005.

[16] S. Hansson and M. Norton, "The relation between surface roughness and interfacial shear strength for bone-anchored implants. A mathematical model," Journal of Biomechanics, vol. 32, no. 8, pp. 829-836, 1999.

[17] B. Yang, M. Uchida, H.-M. Kim, X. Zhang, and T. Kokubo, "Preparation of bioactive titanium metal via anodic oxidation treatment," Biomaterials, vol. 25, no. 6, pp. 1003-1010, 2004.

[18] Y.-T. Sul, C. Johansson, E. Byon, and T. Albrektsson, "The bone response of oxidized bioactive and non-bioactive titanium implants," Biomaterials, vol. 26, no. 33, pp. 6720-6730, 2005.

[19] Y.-T. Sul, C. Johansson, A. Wennerberg, L.-R. Cho, B.-S. Chang, and T. Albrektsson, "Optimum surface properties of oxidized implants for reinforcement of osseointegration: surface chemistry, oxide thickness, porosity, roughness, and crystal structure," International Journal of Oral and Maxillofacial Implants, vol. 20, no. 3, pp. 349-359, 2005.

[20] Y.-T. Sul, B.-S. Kang, C. Johansson, H.-S. Um, C.-J. Park, and T. Albrektsson, "The roles of surface chemistry and topography in the strength and rate of osseointegration of titanium implants in bone," Journal of Biomedical Materials Research-Part A, vol. 89, no. 4, pp. 942-950, 2009.

[21] C. S. Chen, M. Mrksich, S. Huang, G. M. Whitesides, and D. E. Ingber, "Geometric control of cell life and death," Science, vol. 276, no. 5317, pp. 1425-1428, 1997.

[22] A. J. Engler, S. Sen, H. L. Sweeney, and D. E. Discher, "Matrix elasticity directs stem cell lineage specification," Cell, vol. 126, no. 4, pp. 677-689, 2006.

[23] E. A. Cavalcanti-Adam, A. Micoulet, J. Blümmel, J. Auernheimer, H. Kessler, and J. P. Spatz, "Lateral spacing of integrin ligands influences cell spreading and focal adhesion assembly," European Journal of Cell Biology, vol. 85, no. 3-4, pp. 219-224, 2006.

[24] H.-G. Boyen, G. Kästle, F. Weigl et al., "Oxidation-resistant gold-55 clusters," Science, vol. 297, no. 5586, pp. 1533-1536, 2002. 
[25] M. J. Dalby, D. Giannaras, M. O. Riehle, N. Gadegaard, S. Affrossman, and A. S. G. Curtis, "Rapid fibroblast adhesion to $27 \mathrm{~nm}$ high polymer demixed nano-topography," Biomaterials, vol. 25, no. 1, pp. 77-83, 2004.

[26] M. J. Dalby, D. Pasqui, and S. Affrossman, "Cell response to nano-islands produced by polymer demixing: a brief review," IEE Proceedings Nanobiotechnology, vol. 151, no. 2, pp. 53-61, 2004.

[27] M. J. Dalby, M. O. Riehle, S. J. Yarwood, C. D. W. Wilkinson, and A. S. G. Curtis, "Nucleus alignment and cell signaling in fibroblasts: response to a micro-grooved topography," Experimental Cell Research, vol. 284, no. 2, pp. 274-282, 2003.

[28] T. J. Webster, C. Ergun, R. H. Doremus, R. W. Siegel, and R. Bizios, "Enhanced functions of osteoblasts on nanophase ceramics," Biomaterials, vol. 21, no. 17, pp. 1803-1810, 2000.

[29] A. Wennerpberg and T. Albrektsson, "Implant surfaces beyond micron roughness. Experimental and clinical knowledge of surface topography and surface chemistry," International Dentistry $S A$, vol. 8, pp. 14-18, 2006.

[30] D. H. Shin, T. Shokuhfar, C. K. Choi, S.-H. Lee, and C. Friedrich, "Wettability changes of $\mathrm{TiO}_{2}$ nanotube surfaces," Nanotechnology, vol. 22, no. 31, Article ID 315704, 2011.

[31] J. M. Macak, H. Tsuchiya, L. Taveira, A. Ghicov, and P. Schmuki, "Self-organized nanotubular oxide layers on Ti-6Al-7Nb and Ti-6Al-4V formed by anodization in $\mathrm{NH}_{4} \mathrm{~F}$ solutions," Journal of Biomedical Materials Research Part A, vol. 75, no. 4, pp. 928933, 2005.

[32] K. S. Brammer, S. Oh, C. J. Cobb, L. M. Bjursten, H. V. D. Heyde, and S. Jin, "Improved bone-forming functionality on diametercontrolled $\mathrm{TiO}_{2}$ nanotube surface," Acta Biomaterialia, vol. 5, no. 8, pp. 3215-3223, 2009.

[33] G. Mendonça, D. B. Mendonça, F. J. Aragão, and L. F. Cooper, "Advancing dental implant surface technology-from micronto nanotopography," Biomaterials, vol. 29, no. 28, pp. 3822-3835, 2008.

[34] S.-H. Oh, R. R. Finõnes, C. Daraio, L.-H. Chen, and S. Jin, "Growth of nano-scale hydroxyapatite using chemically treated titanium oxide nanotubes," Biomaterials, vol. 26, no. 24, pp. 4938-4943, 2005.

[35] S. Oh, C. Daraio, L.-H. Chen, T. R. Pisanic, R. R. Fiñones, and S. Jin, "Significantly accelerated osteoblast cell growth on aligned $\mathrm{TiO}_{2}$ nanotubes," Journal of Biomedical Materials Research Part A, vol. 78, no. 1, pp. 97-103, 2006.

[36] S. Oh and S. Jin, "Titanium oxide nanotubes with controlled morphology for enhanced bone growth," Materials Science and Engineering C, vol. 26, no. 8, pp. 1301-1306, 2006.

[37] K. S. Brammer, S. Oh, J. O. Gallagher, and S. Jin, "Enhanced cellular mobility guided by $\mathrm{TiO}_{2}$ nanotube surfaces," Nano Letters, vol. 8, no. 3, pp. 786-793, 2008.

[38] S. Oh, K. S. Brammer, Y. S. J. Li et al., "Stem cell fate dictated solely by altered nanotube dimension," Proceedings of the National Academy of Sciences of the United States of America, vol. 106, no. 7, pp. 2130-2135, 2009.

[39] J. Park, S. Bauer, K. A. Schlegel, F. W. Neukam, K. D. Von Mark, and P. Schmuki, "TiO 2 nanotube surfaces: $15 \mathrm{~nm}$-an optimal length scale of surface topography for cell adhesion and differentiation," Small, vol. 5, no. 6, pp. 666-671, 2009.

[40] J. Park, S. Bauer, K. von der Mark, and P. Schmuki, "Nanosize and vitality: $\mathrm{TiO}_{2}$ nanotube diameter directs cell fate," Nano Letters, vol. 7, no. 6, pp. 1686-1691, 2007.
[41] L. M. Bjursten, L. Rasmusson, S. Oh, G. C. Smith, K. S. Brammer, and S. Jin, "Titanium dioxide nanotubes enhance bone bonding in vivo," Journal of Biomedical Materials Research A, vol. 92, no. 3, pp. 1218-1224, 2010.

[42] C. von Wilmowsky, S. Bauer, R. Lutz et al., "In vivo evaluation of anodic $\mathrm{TiO}_{2}$ nanotubes; an experimental study in the pig," Journal of Biomedical Materials Research B: Applied Biomaterials, vol. 89, no. 1, pp. 165-171, 2009.

[43] M. J. Dalby, N. Gadegaard, A. S. G. Curtis, and R. O. C. Oreffo, "Nanotopographical control of human osteoprogenitor differentiation," Current Stem Cell Research \& Therapy, vol. 2, no. 2, pp. 129-138, 2007.

[44] L. E. McNamara, R. J. McMurray, M. J. P. Biggs, F. Kantawong, R. O. C. Oreffo, and M. J. Dalby, "Nanotopographical control of stem cell differentiation," Journal of Tissue Engineering, vol. 1, no. 1, Article ID 120623, 2010.

[45] N. Fujii, H. Kusakari, and T. Maeda, "A histological study on tissue responses to titanium implantation in rat maxilla: the process of epithelial regeneration and bone reaction," Journal of Periodontology, vol. 69, no. 4, pp. 485-495, 1998.

[46] N. Y. Karimbux, A. Sirakian, H. P. Weber, and I. Nishimura, "A new animal model for molecular biological analysis of the implant-tissue interface: spatial expression of type XII collagen mRNA around a titanium oral implant," The Journal of oral Implantology, vol. 21, no. 2, pp. 107-115, 1995.

[47] T. Futami, N. Fujii, H. Ohnishi et al., "Tissue response to titanium implants in the rat maxilla: ultra structural and histochemical observations of the bone-titanium interface," Journal of Periodontology, vol. 71, no. 2, pp. 287-298, 2000.

[48] J. E. Kenzora, R. E. Steele, Z. H. Yosipovitch, and M. J. Glimcher, "Experimental osteonecrosis of the femoral head in adult rabbits," Clinical Orthopaedics and Related Research, vol. 130, pp. 8-46, 1978.

[49] C. B. Johansson and T. Albrektsson, "A removal torque and histomorphometric study of commercially pure niobium and titanium implants in rabbit bone," Clinical oral Implants Research, vol. 2, no. 1, pp. 24-29, 1991.

[50] T. Ogawa, S. Ozawa, J.-H. Shih et al., "Biomechanical evaluation of osseous implants having different surface topographies in rats," Journal of Dental Research, vol. 79, no. 11, pp. 1857-1863, 2000 

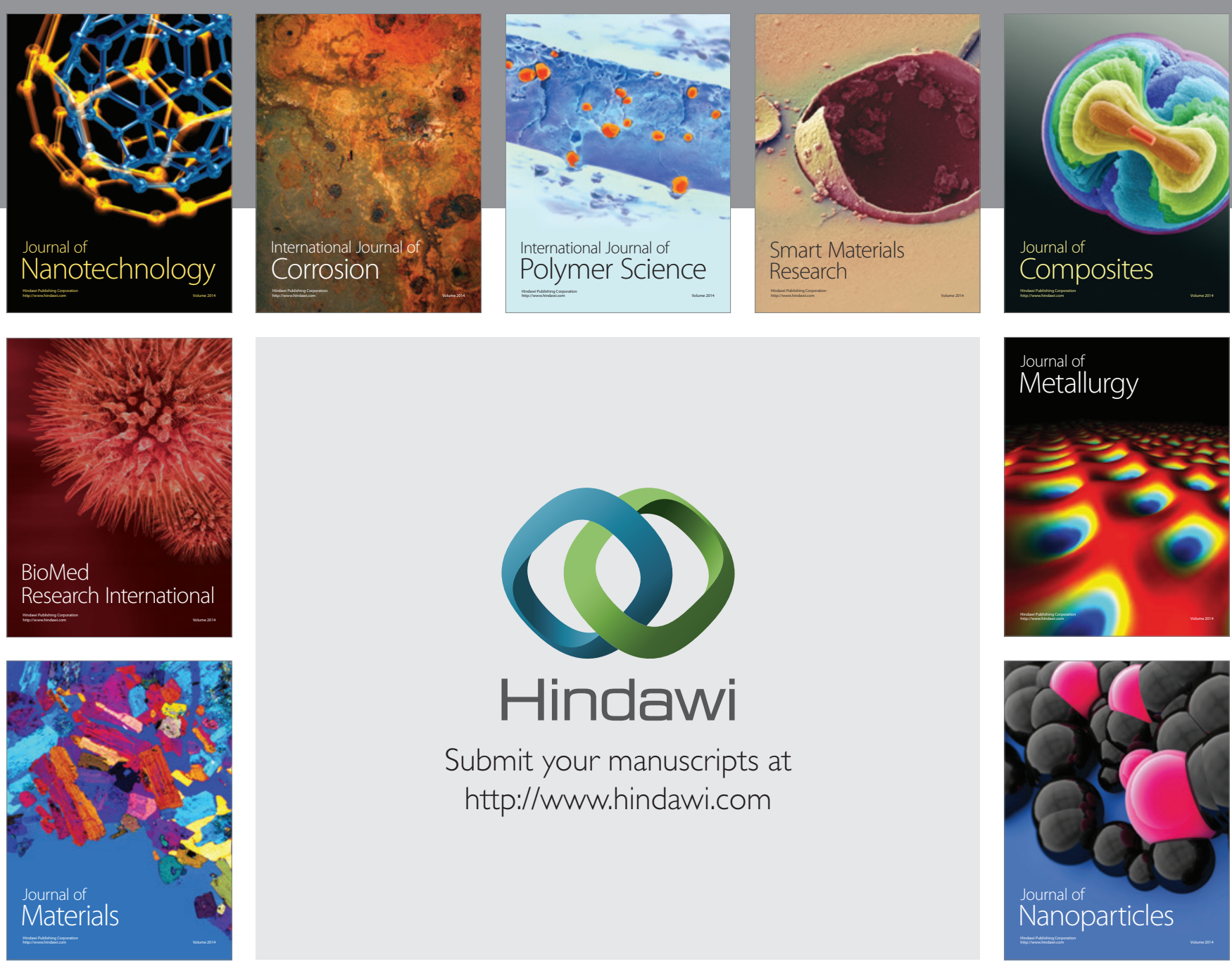

Submit your manuscripts at http://www.hindawi.com
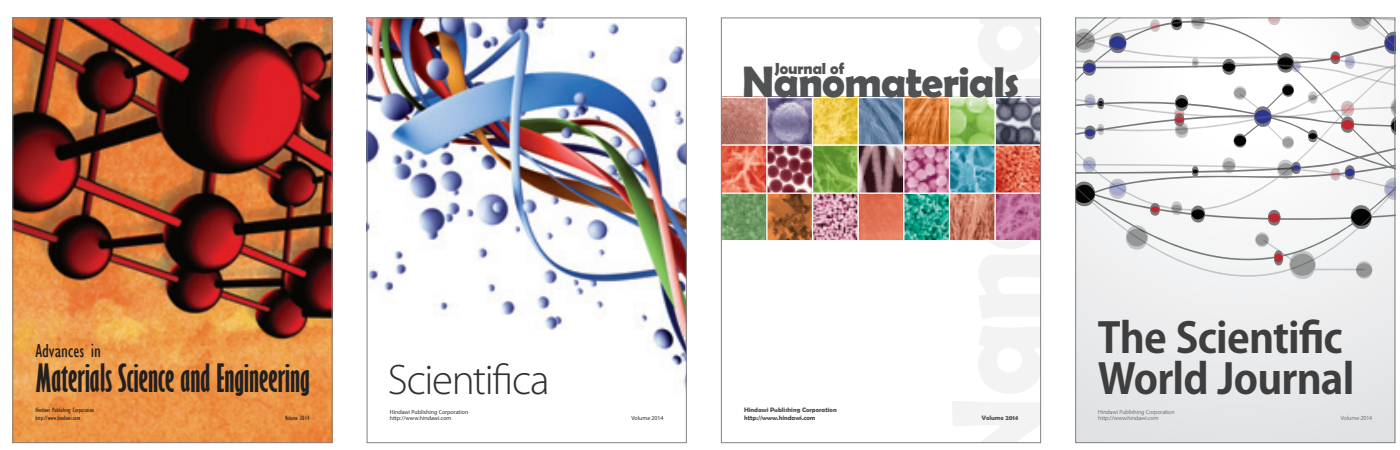

\section{The Scientific World Journal}
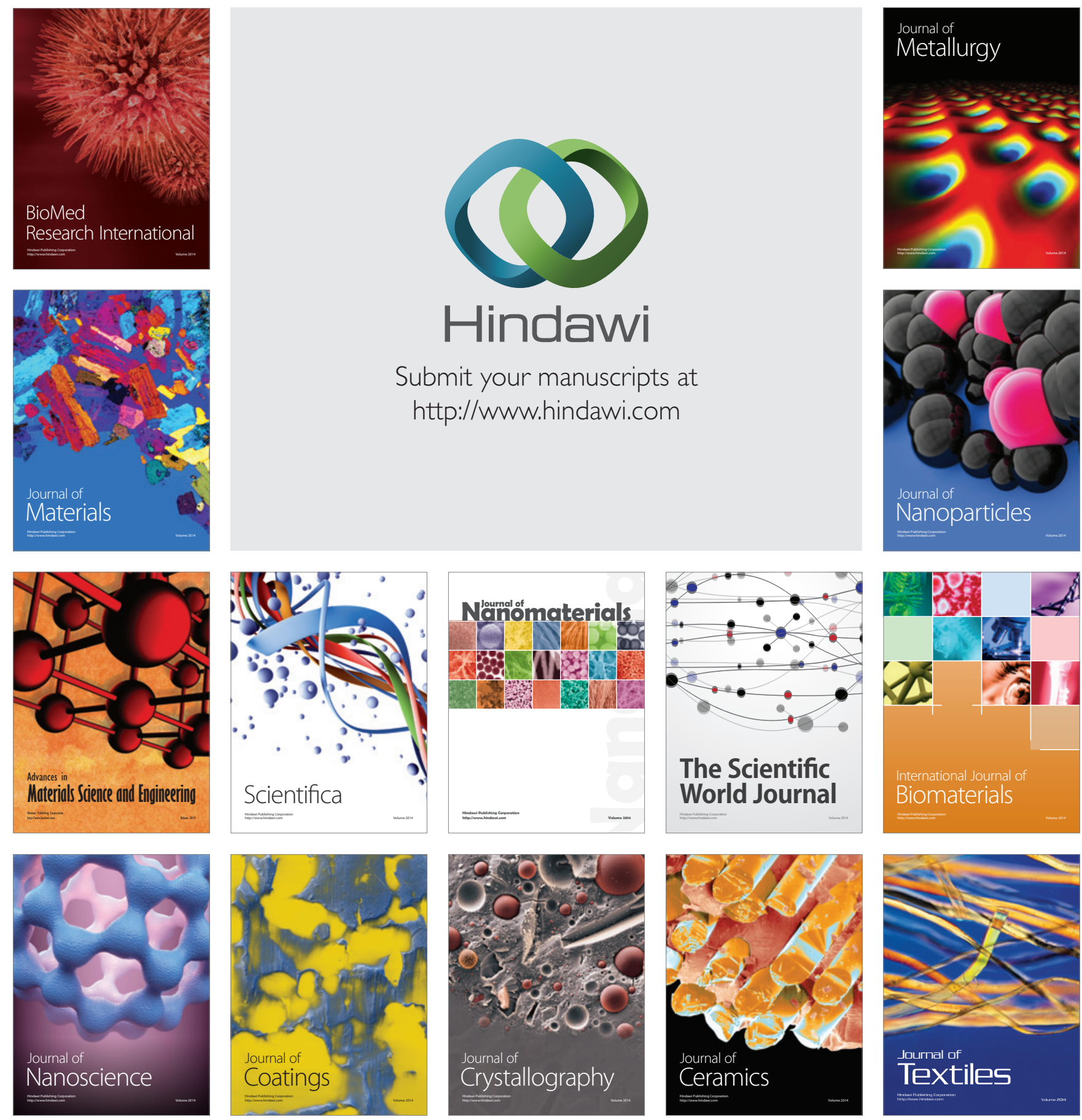